\title{
LA FUNDACIÓN DEL MONASTERIO DE SAN ISIDRO DE CALLOBRE
}

\author{
por \\ JOSÉ LUIS LÓPEZ SANGIL
}

La constante búsqueda por los archivos españoles de documentación referente al Monasterio de Santa María de Monfero, me ha permitido encontrar interesantes pergaminos cuyo contenido aportan un importante caudal de información para la historia eclesiástica gallega.

Una de estas piezas, localizada en la Real Academia Gallega, en La Coruña, me planteó en un principio bastantes interrogantes. Sin clasificar y junto a otros documentos provinientes del legado de Manuel Murguía, apareció en dos fragmentos, que se encontraban sueltos y doblados y en muy mal estado de conservación. La línea de rotura se había producido por el primero de los cuatro pliegues horizontales. Tenía algunos rotos, con falta de pergamino, coincidiendo con los pliegues y las esquinas de las dobleces. Su tamaño era aproximadamente de $50 \mathrm{~cm}$. de ancho por 35 $\mathrm{cm}$. de alto. La letra de finales del siglo XII y lógicamente su texto redactado en latín.

En una primera visión, pude observar que contenía dos documentos, cada uno con sus confirmantes y sus signos propios, aunque ambos escritos por la misma mano. Vamos a comenzar su estudio, que me deparó no pocas sorpresas, intentando definir su autenticidad, la fecha y la realidad de sus confirmantes. Para ello, a partir de ahora, analizaremos el primer documento y a continuación el segundo documento.

"CUADERNOS DE ESTUdiOS GALLEGOS", Tomo XLII, Fascículo 107, Santiago 1995. 


\section{EL PRIMER DOCUMENTO}

Este primer documento describe la fundación del Monasterio de San Isidro de Callobre, que se encontraba situado en el actual Ayuntamiento de Miño, provincia de La Coruña.

Al comenzar su estudio, me encontré con la primera sorpresa de que había abundantes referencias bibliográficas, aunque la mayor parte de ellas se basan en los comentarios y la transcripción que de este documento hace el Códice 259 B del Archivo Histórico Nacional. Este Códice tiene el título de «Tumbo, donación y fundación de este Imperial Monasterio de Monfero y sus cotos y jurisdicciones con las grandezas de dicho Monasterio». Está formado por 42 folios en pergamino de 30,5 x $25,5 \mathrm{~cm}$. Se cree fue escritọ por el monje cisterciense Fray Bernardo Cardillo de Villalpando hacia el año 1617, siendo finalizado por otros autores.

A partir de su folio $10 \mathrm{v}$ dice lo siguiente:

«El Monasterio de San Isidro de Callobre (granja que es de éste de Monfero) fué fundación de un clérigo particular, llamado Sentario. Pusso en él algunos monjes devajo del Instituto y regla de nuestro Padre San Benito, donde vivieron muy pocos años, porque los mesmos religiosos dejaron el Monasterio y se fueron a otros, despues de haber muerto muchos en él. Despues de algunos años en adelante, era de mill ducientos y uno, a primeros de Mayo, hizo donación de su iglesia con todo lo a ella anexo y con otras heredades d'este Monasterio de Monfero, el Conde D. Fernando Pérez de Traba, hijo del Conde Don Pedro de Traba, ayo que fué del Emperador Don Alonso Ramón. Luego, pues, que el dicho Conde hiço la donación a este Monasterio, edificó las ruinas y despojos del antiguo de San Ysidoro, una cassa y palacio sumptuoso junto a la dicha iglesia y hermita, que con título de granja persevera en pié al día de hoy. La carta de fundación es la que se sigue con sus formales palabras.

In nomine Summae, Sanctae et Individuae Trinitatis, Patris Ingeniti, Filiique Unigeniti ac Spiritus Paracleti cuius dispossitione omnia ex nihilo condita sunt. Huic Deo trino et uno, ego Sentarius, servus servorum Dei, minimus me tota devotione committo, animam, corpus commendo. Illi etiam Deo Sanctisque eius eclesiam construere devote decrevi propria poesessione, quae mihi ex antiquo accidit ex portione

"CUADERNOS DE ESTUdIOS GALLEGOS", Tomo XLII, Fascículo 107, Santiago 1995 
avulorum meorum, quam etiam haereditate a Romano Didaz dedit integra pro suo precio, hic est: uno cavalo rodane in quadraginta solidos et una vacca viduata in quindecim solidos. Et ego Romanus Didaz do ipsa haereditate pro hoc precio, et pro remedio animae meae et parentum meorum et pro peccatis meis quae tibi manifestavi et confessus sum, ut habeas me semper in mente tua tu et sucessores tui.

Est autem eclessia a me fundata in finibus marinis Galleciae, in territorio Prucius sub episcopo Sedis Apostolicae Sancti lacobi, et est determinata per suos terminos antiquos, id est, per terminos de Pousadoira, et item per in directum terminum de Minudales, et per aqua de aquata, et inde ad ipsas forcatas de ipsas aquas, et inde ad fontem de ipsa aquata aqua, et inde ad ipsa Anta de ipso Plano et ad Saxos de ipsa Rugitoria de super Sancta Eugenia, et ex alia parte flumine Lamber uno agro de tres modios, tres cassales, Loberiz et Sandim et Cantom, medietate de illis, et Vigo cun suos Cassales, ad sunt mirati Petri Jilbesi, Rodessindi medietate sub aula Sancti Ioannis de Callobre, medio de uno cassale sub aula Sancti Georgii de Torres, tres cassales, uno medio, alio integre et alio mediato, et in alio loco praenominato Villare de Idrales. De una vouça de tres modios et per aquam de Lobegildi usque flumen Lambre.

Hanc igitur haereditatem omnem de super memoratam, tan cultam quam incultam, Deo excelso Trino et Uno, offero et concedo devote et ecclessiam quae ibi in honorem ipsius Dei omnipotentis et in nomine Sancti Ysidoris martyris et conffessoris fabricavi, ut ibi servi Dei sub norma Sancti Benedicti regula Deo perpetualiter famulentur, ac sub tuitiones Sedis Appostolicae Sancti Iacobi ipsa permaneat. Haec omnia iam dicta pro redemptione animae mee Deo omnipotenti, vivo et vero, die dedicationis ipssius eclessiae ego Sentarius devotus offero in dote altaris habens etiam adornata ecclessia et unum calicem et crucem coronamque argentoam, vestimenta sacerdotalia, tam linea quam serica bina, sacramentorum librum unum, antiphonales duos et alio comiti et missale, et unius psalterium, et unum ordinarium sive himnorum. Ad substentationem ibidem Deo famulantium equas tres cum suos fillos, iuga boum tria, vaccas tres cum suos filios, triginta ovelias, cabras decem, et caetera movilia quae necessaria sunt, in obsequio Deo sunt donata, ut habeant et possideant servi Dei ibidem viventes sub regula Sancti Benedicti, ibi eorum vitae perenni. Si quis autem ex gente mea vel aliena hoc testamentum infregerit, sedeat excommunicatus et damnatus cum Iuda Domini traditore in inferno. Facta series testamenti 
huius seu dotis ecclesiae Sancti Yssidori die dominico ipssius dedicationis, era millessimi et quinquagessimi sex et quotum octavum idus Septembris. Ego Sentarius, servus servorum Dei minimus, seriem testamenti seu dedicationis ecclesiae manu propria confirmo. Regnante Adefonso in Toledo. Ego episcopus Amor Luccensse sedis confirmo. Episcopus Gundisalvus Mindonensis confirmat. Archidiaconus Joannes Roderiguez confirmat el laudat. Segeredus, princeps terrae, confirmat. Et alli plures que viderunt. Bermudus qui notavit.

Por esta donación va demarcando la jurisdicción y coto redondo de san Ysidoro de Callobre, según en ella se ve, y en esta forma la llebaba el Monasterio antiguamente; pero ahora es toda la propiedad nuestra y la jurisdicción se demarca asi: Comienza en la entrada de la Corredoira que biene de Posadoira para las Vigas Vellas en la Bicha y Cruz de Palo, y va por el rego abago circundando la huerta por el muro, de allí circunda la vodega y la hermita y sale por detrás a la esquina del palacio, y toda la heredad que hará un ferrado de pan de sembradura y por aguas vertientes de la casa y era sale a la corredoira de la fonte de la Bicha y Cruz, en donde se empeçó a demarcar.

La propiedad que con esta jurisdicción tiene el Monasterio en este coto de Callobre, se la donaron con el Monasterio de san Issidro los arriva referidos».

Hasta aquí lo que trae el citado Códice 259B. Comparado con el documento original, coincide prácticamente el texto, aunque con pequeñas variantes que no afectan su interpretación.

Sin embargo, tenemos que hacer varios comentarios que en una primera impresión podrían cuestionar su validez. El primero es la fecha, pues en el texto del Códice 259B se lee claramente «era 1056, octavos idus de Septiembres, lo que corresponde al 6 de septiembre de 1018. Si observamos el documento original, en el pergamino se lee sin dificultad «Era MLVI et quot VIII idus Septembris». Es decir, coincide con la transcripción del Códice. Vamos entonces a acudir a las referencias bibliográficas.

El primero es hablar de este documento es Fr. Manuel Risco, quien escribe':

España Sagrada, Tomo XL, página 185.

"CUADERNOS DE ESTUDIOS GALLEGOS", Tomo XLII, Fascículo 107, Santiago 1995. 
"En el mismo año de 1088 fué depuesto de la sede Iriense su Obispo Don Diego en el Concilio que se celebró en Husillos. Por esta deposición se nombró a Amor Obispo de Lugo Vicario de aquella Sede, y como tal consagró la Iglesia del Monasterio de San Isidro de Callobre en territorio de Pruzos, cerca del rio Lambe. Consta asi de la escritura de fundación y dotación que hizo en favor del expresado Monasterio el siervo de Dios Sertario, la qual está confirmada por nuestro Obispo, y por Gonzalo de Mondoñedo. Todo lo qual y la unión del referido Monasterio al de santa María de Monfero hecha por el Conde Don Fernando González se lee en el fol. 10 del tumbo de Monfero, y cax. de Callobre». (Se refiere al citado Códice 259B).

Hacemos notar que ha corregido, la fecha y pone la del año 1088, probablemente basándose en otros datos, como son los confirmantes.

López Ferreiro no podía dejar de comentar este documento ${ }^{2}$, hasta tal punto que lo transcribe, copiándolo igualmente del Códice $259 \mathrm{~B}$, y comenta que cree que la fecha del P. Risco está equivocada, pues el 6 de Diciembre de 1088 no cayó en domingo, y el primer año de los siguientes en que esto ocurrió fué el de 1092, por lo que dice que ese es el año correcto. Sin embargo cometió el error de considerar el mes de Diciembre cuando lo correcto es el de Septiembre, tal como aparece claramente en el documento. En la misma obra ${ }^{3}$ dice que fué el Obispo de Lugo, D. Amor, el que consagró la iglesia de Callobre, sita en tierra de Pruzos, que había sido fundada por el piadoso presbítero Sentarius, continuando que: "Como la Sede Compostelana se hallaba a la sazón vacante, sin duda por ésto Sentario con autorización del Arcediano Juan Rodríguez invitó al Obispo de Lugo para hacer la consagración».

Otro autor que cita este documento es Linaje Conde ${ }^{4}$, que comete el error de situar Callobre en la Estrada, Pontevedra, pero aún así hace los siguientes comentarios: «En la feligresia de San Martín de Callobre, (en La Estrada, Pontevedra), acaso en el año 1092, fecha sin confirmar, el que se llama "servus servorum dei Sertarius", dice fundarlo en el terreno

\footnotetext{
${ }^{2}$ Historia de la Santa A.M. Iglesia de Santiago de Compostela. Tomo III. Apéndice VI.

${ }^{3}$ Ibid. Tomo III. Página 179.

${ }^{4}$ Los origenes del Monacato Benedictino en la Peninsula Ibérica. León 1973. Tomo III. Página 113.
}

"CUADERNOS DE ESTUDIOS GALLEGOS", Tomo XLII, Fascículo 107, Santiago 1995 


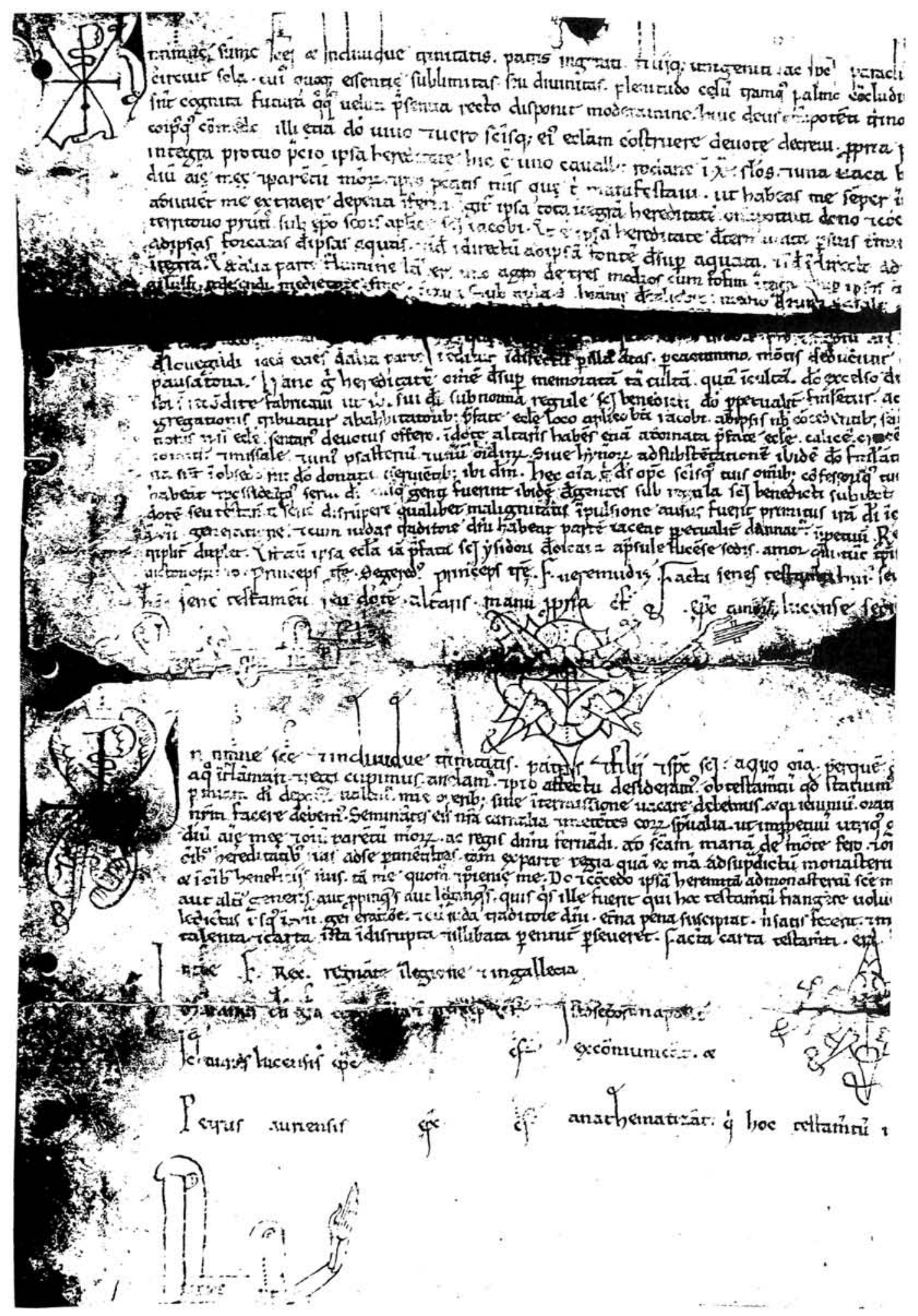




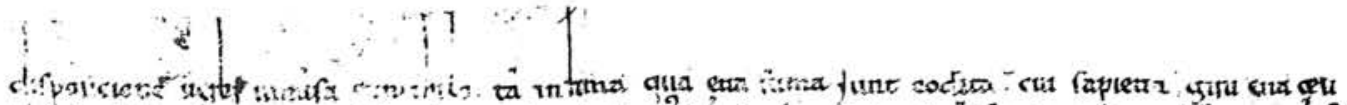

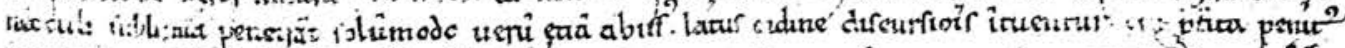

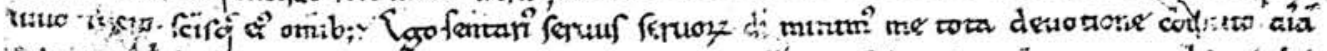

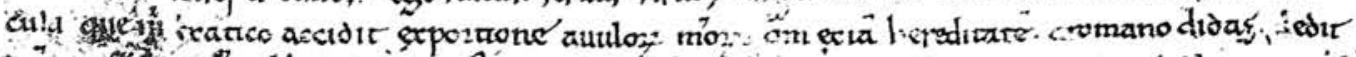

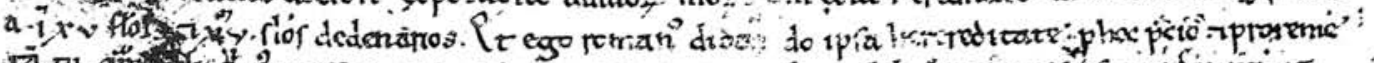

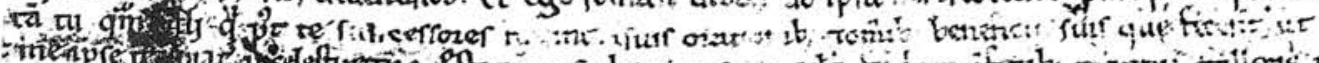

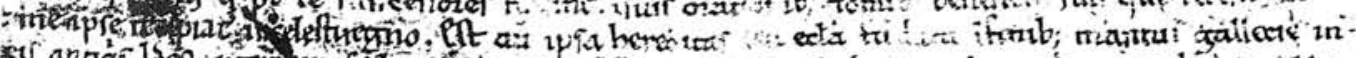

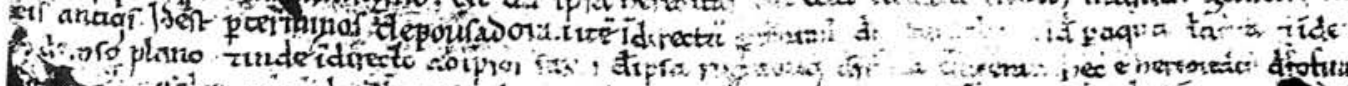

-
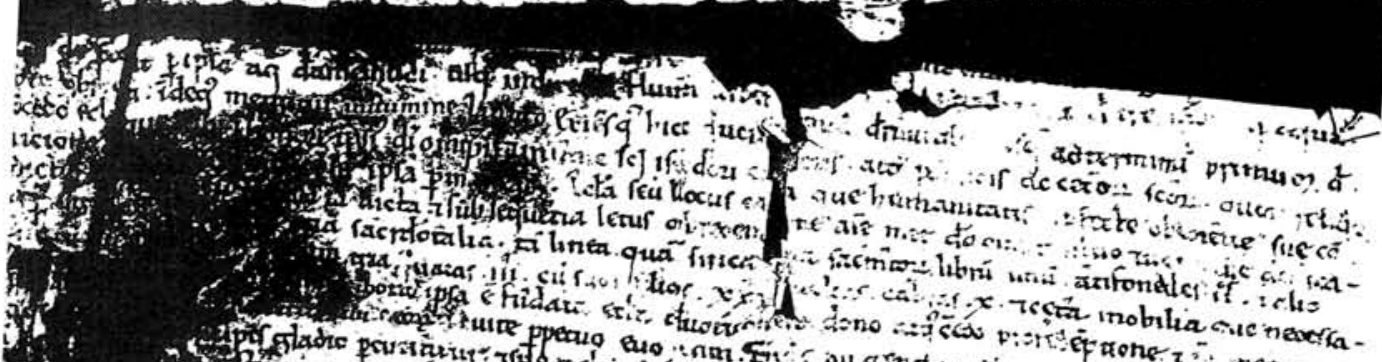

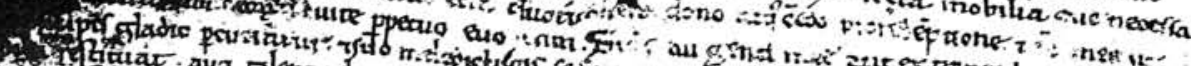

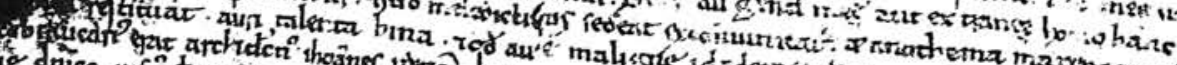

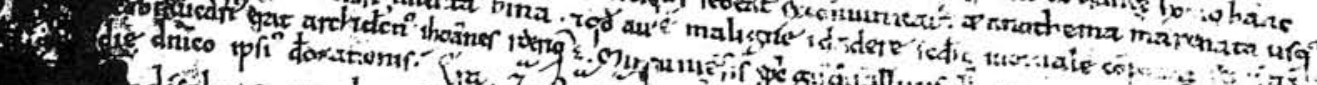

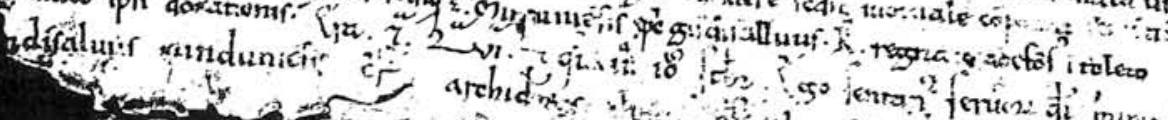

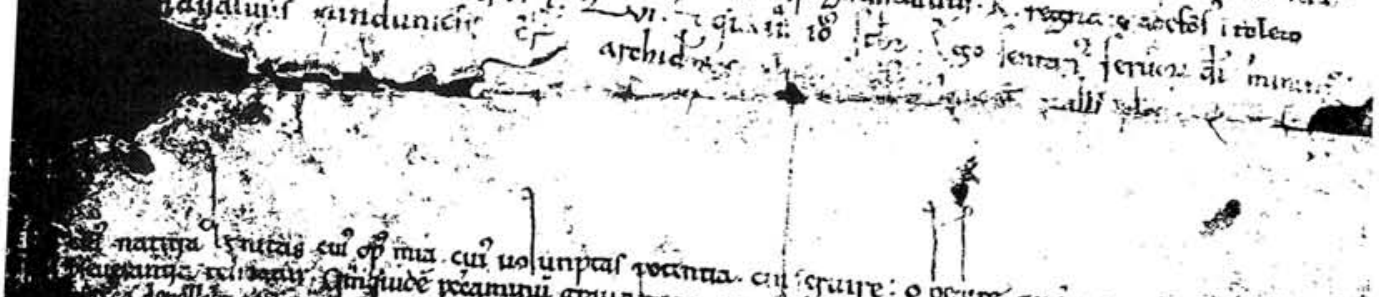

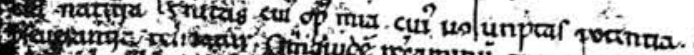

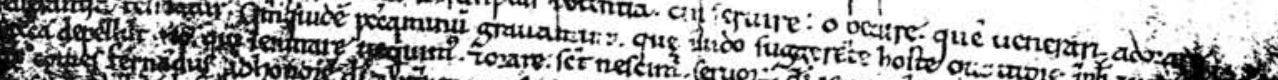

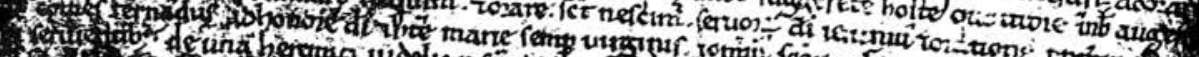

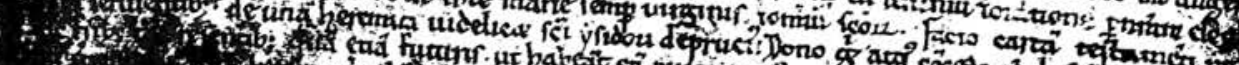

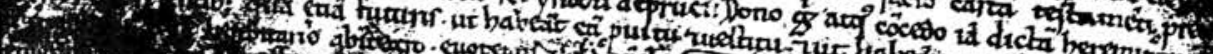

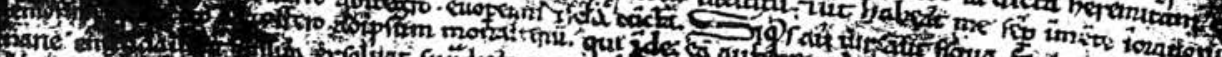

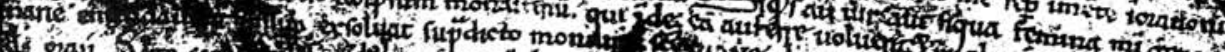

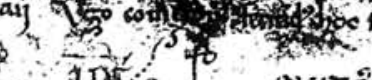

(x)
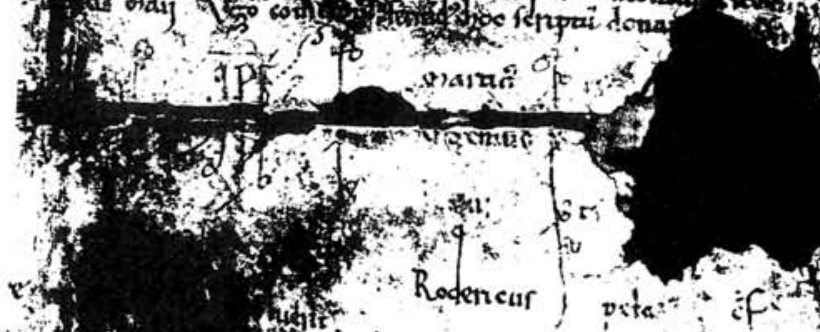

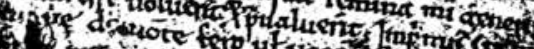

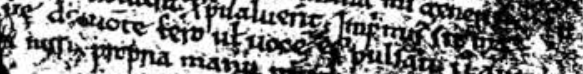

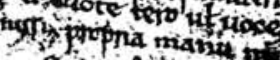

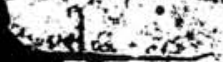

$=-?$

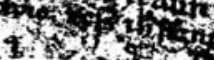

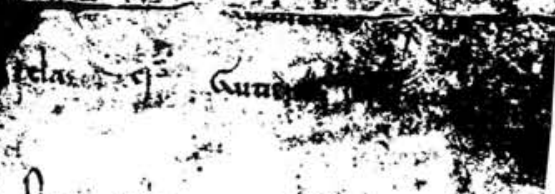

thistit.

$\sin 340$

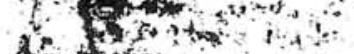

Afonton?

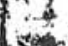

iton. $\therefore$ $\cdots$

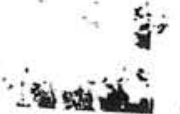

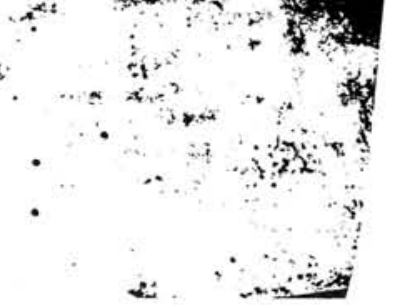


dado por el tambien otorgante Romano Didaz, "est autem ecclessia a me fundata in finibus marinis Galleciae, in territorius Prucius, sub episcopo sedis apostolice Iacobi et es determinata per suos terminos antiquos, id est, per terminos de Pousadoira, et item per indirectum terminum de Minudales... et ad saxos de ipsa rugitoria de Super Sancta"». En la misma obra ${ }^{5}$, dice sobre la misma iglesia de San Isidro de Callobre que: «...el que llaman Sentarius, servus servorum dei, declara haber construido en una heredad adquirida en parte de sus ascendientes, y en parte comprada a Romano Diaz, in finibus marinis Galleciae, in territorio Brucius, sub episcopo sedis apostolice Iacobi, una iglesia dedicada a San Isidro, con el fin de que ubi servi dei, sub norma sancti Benedicti regula,...». Como se ve, Linaje Conde se limita posiblemente a transcribir lo ya citado por López Ferreiro.

Otros comentarios sobre este primer documento de la fundación de Callobre aparecen en la Tesis Doctoral sobre el Monasterio de Monfero de López Robles ${ }^{6}$, en la que comenta, despues de hacer una regesta del documento y adelantar la fecha al 6 de Septiembre del año 918, que: «Evidentemente la fecha propuesta por López Ferreiro es errónea... aparte del cálculo matemático, se evidencia en que el 6 de Septiembre de 1092 fué lunes». En mi opinión, la fecha del año 918, tal como veremos despues es imposible. Este mismo autor, en la página 383, en su apéndice IX, transcribe el documento al igual que López Ferreiro, y al final de la transcripción dice: "Como puede fácilmente demostrarse este documento no es de absoluta garantía. Tiene inexactitudes que saltan a la vista a partir de la data y sobre todo en la relación de confirmantes. Si lo aportamos aqui es porque dá noticia de la fundación del Monasterio de Callobre. Puede a lo más ser considerado como un falso diplomático que contiene en esencia un hecho histórico».

Más comentarios aparecen en el libro de Antonio García Conde 7 , en donde se dice: «... para completar la historia de D. Amor, en 1088 se celebró el Concilio de Husillos donde fué depuesto D. Diego de Iría y se

\footnotetext{
${ }^{5}$ Ibid. Tomo II. Página 738.

${ }^{6}$ Tesis Doctoral presentada en la Universidad de Granada en 1982. Página 162. Inédita.

${ }^{7}$ Antonio GARCÍA CONDE y Amador LÓPEZ VALCÁRCEL. Episcopologio Lucense Lugo 1991. Página 114.
}

"CUADERNOS DE ESTUDIOS GALLEGOS", Tomo XLII, Fascículo 107, Santiago 1995. 
nombró a D. Amor vicario o administrador de aquella sede y como tal consagró la iglesia del Monasterio de Callobre en Pruzos cerca del río Lambre, como consta de la escritura de fundación de dicho Monasterio por Sertario».

Agotado este repaso a las referencias bibliográficas, analizemos ahora la datación de este primer documento. Tal como dijimos anteriormente la fecha aparece claramente en el mismo, sin que se observen correcciones o raspados en el pergamino. Por ello, vamos a estudiar la relación de confirmantes, cuyas fechas de mandato no coinciden en absoluto con el año 1018, y todavía menos con el 918.

Entre los confirmantes están: El Rey Alfonso VI que reinó en 10651109, el obispo Gundisalvo de Mondoñedo que gobernó su diócesis en 1071-1108, y el obispo Amor de Lugo que lo hizo a su vez en 1088-1095.

La fecha de este documento debe de estar por lo tanto en el período del obispo Amor, y casi con total probabilidad en el año 1088, que es la que citan el P. Risco y García Conde, que tuvieron a su alcance otras fuentes.

Pero vamos a fijarnos en otro de los confirmantes: «Segeredus, princeps terrae, confirmat». ¿Quien era este personaje?. Es sin duda Segeredo Aloito, marido de Adosinda Arias, y en su época uno de los hombres más ricos de Galicia, como lo demuestra la importante donación que junto con su mujer hizo al Monasterio de Cines, próximo a Oza de los Ríos, en la provincia de La Coruña, en el año 1063. De Segeredo, descienden los fundadores del Monasterio de Monfero, y por otra rama, Dña. Urraca Froilaz, esposa de D. Pedro Froilaz, Conde de Traba. Segeredo llegó a intitularse Príncipe, y así lo comenta Vaamonde Lores ${ }^{8}$, que además dice: "Así consta de la carta de fundación del Monasterio de San Isidro de Callobre, su fecha 6 de diciembre de 1088». Nuevamente nos hemos encontrado con el año de 1088 , y con un personaje coincidente con esta fecha.

Por todo ello, creemos que podemos afirmar que la fecha de la fundación del Monasterio de San Isidro de Callobre fué el 6 de Septiembre de 1088, sin que encontremos, por el momento, una explicación lógica a la fecha de 1018 que aparece en el documento de la Real Academia Gallega que hemos venido estudiando. El fundador fue el religioso Sertario, que

${ }^{8}$ VAAMONDE LORES. Ferrol y Puentedeume. La Conuña 1909. Página 3.

"CUADERNOS DE ESTUDIOS GALLEGOS", Tomo XLII, Fascículo 107, Santiago 1995 
donó sus bienes, los cuales, junto a los provinientes de Romanus Didaz, permitieron la consagración, en la fecha citada, por D. Amor, obispo de Lugo. La vida del Monasterio fue breve, solo algunos años, siendo abandonado por los religiosos benedictinos tras el fallecimiento de varios de ellos. El edificio se convirtió en ruinas, y es el Conde D. Fernando, quien aprovechando los restos edificó una casa y «palacio» junto a la iglesia o ermita, que más tarde se convirtió en Granja del Monasterio de Monfero.

\section{EL SEGUNDO DOCUMENTO}

Pasemos ahora a estudiar el segundo documento que figura en nuestro pergamino de la Real Academia Gạllega.

La localización en el Archivo Histórico Municipal de La Coruña, en el año 1994, de un inventario de la documentación existente en el archivo del Monasterio de Monfero, realizado en 1833, poco antes de la desamortización, por el Abad Fr. Ambrosio Iglesias, me ha permitido ordenar por «cajones», tal como se conservaban en el Monasterio, los pergaminos del mismo. En el cajón de Callobre, con el título de «San Juan y San Isidro de Callobre» aparece en primer lugar: «N $N^{\circ} 1,2$ y 4.-En 1163 a 1 de Mayo el Conde D. Fernando de Traba donó a este Monasterio la hermita de San Isidro de Callobre con toda su heredad y jurisdicción».

La numeración de los documentos de este índice de 1833, figura siempre con caracteres numéricos grandes en la parte posterior de cada pergamino. En nuestro documento, en una esquina, aparece el $\mathrm{N}^{\circ} 4$, con la palabra Callobre próxima. Existen, además, con letra más moderna, también en su parte posterior, las siguientes anotaciones: «Donación de la hermita de San Ysidro que fué Monasterio de la Orden de San Benito. Granja de San Ysidro de Callobre» y en otro lugar «Donación del Conde D. Fernando en que dá al Monasterio la ermita de San Isidro y fúndose dicha ermita en Monasterio de Nuestro Padre San Benito por Sertario en que le dá mucha hacienda en el año 1018 y a éste Monasterio la dío el Conde en el año 1173». Hemos visto, cuando estudiamos el primer documento, que la fecha de 1018 no es posible, y veremos que la de 1173 tampoco es correcta.

Sin embargo, vamos a averiguar antes cuales son los documentos $\mathrm{N}^{\circ} 1$ y 2 que cita el índice de 1833. Después de una laboriosa búsqueda, en la que revisé los documentos del Monasterio de Monfero que se conservan en el Archivo del Reino de Galicia, Real Academia Gallega y Archivo 
Histórico Nacional, aparecieron en éste último ${ }^{9}$, los dos documentos, en los que en su parte posterior figura los $\mathrm{N}^{\mathrm{o}} 1$ y 2 respectivamente.

El N ${ }^{0} 1$ es un pergamino de $18 \times 22 \mathrm{~cm}$. y figura en la Carpeta $497 \mathrm{con}$ el $\mathrm{N}^{\mathrm{o}}$ 8. Su letra aparenta ser del siglo XIV. Se trata claramente de una copia del original, que es precisamente el $\mathrm{N}^{\mathrm{o}} 2$ del cajón de Callobre. En su parte posterior tiene la siguiente anotación: «La era es de 1201 que restados 38 corresponde al año de Jesucristo de 1163 y no de 1173». Está claro que ya el monje archivero se dio cuenta del error y corrigió la fecha.

El No 2 es un pergamino de $16 \times 25 \mathrm{~cm}$. y figura en la misma Carpeta 497 con el No 9 . Su letra es del siglo XII y tiene todo el aspecto de ser un original. En su parte posterior tiene la siguiente anotación: «Donación del Conde D. Fernando de la ermita de San Isidro...».

Ambos documentos, $\mathrm{N}^{\circ} 1$ y 2 , tienen algunas partes del texto borrosas, así que acudiremos a la transcripción que hizo de los mismos Reigosa Lorenzo $^{10}$ :

"Christus. In Nomine Sancte et Individue Trinitatis Patris et Filii et Spiritus Sancti, a quo omnia, per quem omnia, in que omnia, cuius natura bonitas, cuius opus misericordia, cuis voluptas potentia, cui servire, obedire quem venerari, adorare, a quo inflamare regi cupimus, anelamus et pio affectu desideramus. Hoc testamentum quos statuimus indisolubili perseverantia teneatur. Quem quidem peccaminum gravamina que invido suggerente hoste in nobis augemus per misericordia Dei deponere valemus misericordie operibus sine intermissione vacare debemus, et quia ieiunium, oratio et elemosina peccatum depellunt nos qui ieiunare nequimus et orare sicut Opportet nescimus, servorum Dei ieiunium et orationes per nostram elemosina facere debemus semi nantes eis nostra carnalia et meritentes eorum spiritualia, ut in perpetum utrique glorificemur. Igitur ego Comes Fernandus ad onorem Dei et Beate Marie semper Virginis et omnium Sanctorum facio testamentum pro remedio anime mee et omnium parentum meorum ac Regis donni Fernandi, ad Sancta Mariam de Montefero et omnibus fratribus Deo ibi servientibus, de una heremita

\footnotetext{
${ }^{9}$ Archivo Histórico Nacional. Clero. Carpeta 497, Nº 8 y 9.

${ }^{10}$ Reigosa Lorenzo. Tesis Doctoral sobre el Monasterio de Santa María de Monfero, presentada en la Universidad de Madrid en el año 1948. Inédita.
}

"CUADERNOS DE ESTUDIOS GALLEGOS", Tomo XLII, Fascículo 107, Santiago 1995. 
videlicet Sancti Isidori de prucis. Dono igitur atque concedo dic tam heremitam cum omnibus ad se pertinentibus hereditatibus, tam ex parte regia quam ex mea ad supradictum Monasterium de Montefero ac fratribus tam presentibus quam etiam futuris, ut habeant eam et possideant iure hereditario. Si quis autem viraut mulier mei generis, aut alterius germinis, hoc nostre elemosine testamentum irrumpere aut admullare temptaverit et prevaluerit, sit anatema maranata et cum Iuda traditore in perpetuum dampnatus nisi satisfecerit et male acta plenarie emendaverit. Insuper exsolvat supradicto Monasterio Sancte Marie de Montefero, vel voci eius pulsanti duo auri talenta, et carta ista indisrupta et illibata perhenniter perseveret. Facta carta testamenti era MCCI. Regnante donno Fernando in Legione et Gallecia et in Asturiis. Ego Comes Fernandus hoc scriptum donationis quod fieri iussi propria manu roboro et Cf. Martinus Dei gratia Compostellanus archiepiscopus Cf. Iohanes Dei gratia Lucensis episcopus Cf. Petrus Dei gratia Auriensis episcopus Cf. Menendus Pelagii Cf. Gundisalvus Pelagii Cf. Ovecus Pelagii Cf. Guterrus Guestrariz Cf. Rodericus (Pelagii) Cf. Numerius Pelagii Cf. Signum».

Si se compara este texto con el del $\mathrm{N}^{\circ} 4$, documento de la Real Academia Gallega que hemos venido estudiando, se aprecian pequeñas diferencias. Si en el $\mathrm{N}^{\circ} 2$ dice «facio testamentum» en el $\mathrm{N}^{\circ} 4$ dice «Facta carta testamenti», sin que pueda establecerse cual es el original y cual es la copia. Si es importante, en cambio, la datación, pues en el $\mathrm{N}^{\mathrm{o}} 4$ pone día, mes y año "Facta carta testamenti era MCCI kds may», es decir 1 de Mayo de 1163. Veamos si coincide esta fecha con los confirmantes: El obispo orensano Petrus, ocupó la Sede entre 1157-1169 y el arzobispo de Santiago Martín entre 1156-1160.

En principio coincide la del obispo orensano, pero en cambio la del arzobispo de Santiago aparentemente no es coincidente con la fecha que figura en el documento. Ello nos llevó a analizar su trayectoria. Sabemos que en el año 1160 fue destituido por el Rey Fernando II, y fue electo D. Fernando Fernández. Sin embargo, don Martín, continuó figurando y firmando como arzobispo de Santiago, hasta que fue restituido en su cargo el 5 de septiembre de 1167. Es decir, que sí pudo confirmar este documento en 1163, lo cual demuestra una total coincidencia entre la fecha del documento, el 1 de Mayo de 1163, y los períodos en que los confirmantes ejercieron en sus cargos. 
Sin embargo, el documento nos depara una última sorpresa. Tal como transcribimos anteriormente, el Códice 259B del A.H.N. dice que «... hizo donación de su iglesia con todo lo a ella anexo y con otras heredades d'este Monasterio de Monfero, el Conde d. Fernando Pérez de Traba, hijo del Conde Don Pedro de Traba...». Lo mismo dice el índice del archivo del Monasterio de Monfero del año 1833, que también hemos transcrito. Pero sabemos que el Conde Fernando Pérez de Traba falleció el 1 de Noviembre de 1155. Por lo tanto no es el donante. Pero si nos fijamos bien, el documento $\mathrm{N}^{\circ} 4$, así como el $\mathrm{N}^{\circ} 1$ y 2 , citan a un Conde Fernando, sin añadir más datos sobre su personalidad. Es decir, el redactor del Tumbo y el del índice no comprobaron que en esa fecha este Conde don Fernando Pérez de Traba ya había fallecido, y simplemente lo abribuyeron el personaje para ellos más conocido. Volvamos a recordar entonces al P. Risco que habla, tal como decíamos anteriormente, del Conde don Fernando González. Este era hijo de don Fernando Pérez de Traba y doña Sancha González de Lara. Sabemos que vivía en 1162 y que en 1163 figura como Conde de Trastamara. Así, por ejemplo, recordemos como en un documento del año 1165, que es una donación de D. Fernando II a la iglesia compostelana de la Tierra de Deza, en desagravio por las injurias que había consentido que se le hiciesen con motivo de la aversión que tomara al Arzobispo D. Martín, figura como confirmante Comes Fernandus Gunzalvi de Gallecia ${ }^{11}$. Como vemos van coincidiendo en la fecha del documento todos los personajes que en él se citan: el obispo orensano Petrus, el arzobispo de Santiago Martín con la lucha de éste con Fernando II y el Conde don Fernando González, que dos años más tarde confirmaba un nuevo documento con participación de algunos de nuestros protagonistas. Todo ello reafirma el comentario del P. Risco en cuanto a la fecha de 1088 para la fundación de Callobre en el primer documento y que el segundo fue una donación del Conde Fernando González, lo cual nos hace suponer que tuvo delante suya unas fuentes documentales más amplias que las nuestras.

Llegamos por lo tanto a las conclusiones finales de este segundo documento que se encuentra en el pergamino que se conserva en la Real Academia Gallega: La donación de San Isidro de Callobre al Monasterio de Santa María de Monfero tuvo lugar el 1 de Mayo de 1163 y fue realizado por el Conde D. Fernando González.

\footnotetext{
"LÓPEZ FERREIRO. Historia... Tomo III. Apéndice 35.
} 


\section{CONCLUSIONES}

Finalizamos así este largo proceso de investigación que nos ha permitido corregir y aclarar el contenido del documento que localizamos en la Real Academia Gallega. Como resumen, podemos decir que la fecha de la fundación del Monasterio de San Isidro de Callobre, uno de los primeros monasterios benedictinos de Galicia, fue el 6 de Septiembre de 1088 . El fundador fue el religioso Sertario, que donó sus bienes, los cuales, junto a los provinientes de Romanus Didaz, permitieron la consagración, en la fecha citada, por D. Amor, obispo de Lugo. La vida del Monasterio fue breve, solo algunos años, siendo abandonado por los religiosos benedictinos tras el fallecimiento de varios de ellos. El edificio se convirtió en ruinas, y es el Conde don Fernando González, hijo de don Fernando Pérez de Traba, quien el 1 de Mayo de 1163, aprovechando los restos, edificó una casa y «palacio» junto a la iglesia o ermita, donando todo ello al Monasterio de Santa María de Monfero. Más tarde, este recinto, se convirtió en Granja cisterciense del mismo Monasterio.

La Granja de San Isidro de Callobre tuvo larga vida, incrementando fuertemente sus posesiones mediante donaciones, permutas y compras, tal como refleja la abundante documentación que se conserva sobre el Monasterio de Monfero en los archivos anteriormente citados. En el año 1328 fue aforada la encomienda de sus tierras, con el claro objeto de defender su propiedad. Como todas las demás posesiones de los monjes blancos, con la desamortización, en el año 1835, dejó de depender de la Orden del Císter.

Terminamos aquí esta larga exposición sobre un olvidado documento en pergamino, cuyo estudio fue largo y laborioso, recordando en algunos momentos una labor detectivesca, pero que al final permite modestamente aportar un granito de arena más al conocimiento de la historia del monacato gallego en el siglo XI de nuestra Galicia. 